\title{
Manual Hyperinflation: Is It Effective?
}

Patients receiving invasive mechanical ventilation who are unable to breathe spontaneously or produce an effective cough may retain pulmonary secretions leading to bronchial obstruction and atelectasis with the attendant adverse effects. ${ }^{1,2}$ To enhance airway clearance, a maneuver known as manual hyperinflation, which involves lung ventilation with a manual resuscitator, was first described more than 50 years ago. ${ }^{3}$ By simulating a normal cough, this maneuver is intended to mobilize secretions from smaller airways toward the trachea, where they can be removed easily with airway suction. ${ }^{1}$ Manual hyperinflation was (and perhaps still is) used primarily in a routine and prophylactic basis with airway suctioning to achieve mucus clearance. ${ }^{4}$ However, considering the current consensus on endotracheal suctioning of mechanically ventilated patients, which only recommends this procedure when there are signs of accumulated pulmonary secretions, ${ }^{5}$ it appears contradictory to use manual hyperinflation as a routine in clinical practice.

Manual hyperinflation has also been applied with a second aim: to open collapsed lung units not associated with airway secretion obstruction in surgical patients. ${ }^{6}$ However, taking into account the accumulated evidence that lung hyperinflation causes only transitory alveolar recruitment (ie, for a matter of seconds) if it is not followed by sufficient PEEP, ${ }^{7-9}$ it seems prudent to use the ventilator to improve lung volume instead of manual hyperinflation.

The fact that manual hyperinflation is also applied to recruit alveoli in patients without copious secretions has created confusion in the literature. Its use, indication, and expected outcomes are frequently mistaken. This might explain, at least in part, why manual hyperinflation has not become a standard practice worldwide, even with the experts' recommendations on how to apply it to remove secretions. ${ }^{4,10,11}$ According to the literature, the maneuver should apply a larger than normal volume (up to 50\%

Dr Carvalho is supported by a scholarship from Fundacao de Amparo a Pesquisa do Estado de São Paulo (FAPESP).

Correspondence: Mauro R Tucci, Laboratório de Investigação Médica 09 (LIM-09), Faculdade de Medicina da Universidade de São Paulo, Av. Dr. Arnaldo, 455, $2^{\circ}$ andar, sala 2144, CEP 01246-903, São Paulo, SP, Brasil. E-mail: mrotucci@gmail.com.

DOI: $10.4187 /$ respcare. 07152 greater than the set tidal volume) with a slow inspiratory flow, followed by an inspiratory pause of 1-2 $\mathrm{s}$ and then a rapid release of the bag to produce high expiratory flow. Inconsistencies in the indication and application of manual hyperinflation may have contributed to the association of manual hyperinflation with only short-term improvements in lung compliance, oxygenation, and secretion clearance but not on important clinical outcomes. ${ }^{1,12}$

See the Original Study on Page 760

At the beginning of the 21 st century, ventilator hyperinflation was proposed as an alternative to manual hyperinflation. ${ }^{13}$ Ventilator hyperinflation is applied with the mechanical ventilator and was designed to mimic manual hyperinflation (ie, the application of a high tidal volume with a low inspiratory flow, an inspiratory pause, and high expiratory flow). Clinical studies have previously compared manual hyperinflation with ventilator hyperinflation and found no significant differences in the amount of secretions recovered, respiratory compliance, or oxygenation. ${ }^{1,12,14}$ However, ventilator hyperinflation does have potential advantages over manual hyperinflation. Because there is no disconnection from the ventilator, ventilator hyperinflation allows PEEP to be maintained and $\mathrm{F}_{\mathrm{IO}_{2}}$ and respiratory mechanics to be monitored.1,14 Despite these potential advantages, manual hyperinflation continues to be more widely used than ventilator hyperinflation. ${ }^{4,14}$

The effectiveness of manual hyperinflation and ventilator hyperinflation is usually evaluated by its capacity to generate an expiratory flow bias (ie, a peak expiratory flow higher than the peak inspiratory flow), which is believed to move secretions toward the central airways through 2-phase gas-liquid transport. ${ }^{15,16}$ The critical factors that affect mucus transport by this mechanism include inspiratory-expiratory air velocity, the viscosity of mucus, and the thickness of the mucus layer. ${ }^{17,18}$ The last criteria, mucus thickness, needs to reach $10 \%$ to $15 \%$ of airway diameter in the large airways; otherwise, the 2-phase gasliquid transport is probably insignificant because the ciliary escalator is sufficient to clear airways with a normal mucus layer. ${ }^{15,17,18}$ To be more precise, the 2-phase transport occurs only if the mucus layer thickness exceeds a critical value, after which transport rises with increasing expiratory flow bias. ${ }^{19}$ 
Another important mechanism to clear airway secretions in mechanically ventilated patients is gravity. Indeed, it plays a well-recognized role in the development and spread of ventilator-associated pneumonia. ${ }^{20}$ It is noteworthy that there is evidence showing that airway clearance in mechanically ventilated patients is primarily driven by gravity rather than by the expiratory flow bias. ${ }^{21}$

In the current issue of RESPIRATORY CARE, Li Bassi et al ${ }^{22}$ compared the effects of manual hyperinflation and ventilator hyperinflation on secretion clearance, gas exchange, pulmonary mechanics, and hemodynamics in pigs with severe bilateral pneumonia. They found that neither maneuver significantly modified pulmonary mechanics or hemodynamic parameters, nor did they improve secretion clearance. Most surprising was that, although both maneuvers increased the expiratory flow bias, this increase did not improve mucus clearance. In some pigs, the mucus clearance rate even deteriorated compared to baseline assessment.

In light of the evidence that higher expiratory bias flow is associated with better mucus transport, ${ }^{11,16,23,24}$ the authors raised a number of hypotheses to explain this unexpected negative result. We will discuss further some of the presented hypotheses and suggest others mainly related to the methods applied. However, despite the methodological concerns raised in this article, it is important to state that their findings may correctly indicate that the use of both maneuvers as secretion clearance techniques should be reappraised.

The primary concern is that, despite the animals having pneumonia and being heavily sedated, they seemed not to have retained secretions, making it difficult for any airway clearance maneuver to show benefit, especially maneuvers that have expiratory flow bias as a main mechanism of action, which relies on mucus thickness to function. This issue is raised because the animals were submitted to tracheal suction $1 \mathrm{~h}$ before intervention, and because the amount of secretions collected, independent of the maneuver applied or day of the assessment, was too small (ie, $<1 \mathrm{~mL}$ ). As a comparison, mechanically ventilated animal models that simulate hypersecretion conditions by infusion of artificial mucus into the bronchi reported instillation of synthetic mucus at a rate of $\sim 1 \mathrm{~mL} / \mathrm{min}$ over 20-90 min to create this scenario, ${ }^{15,19}$ a volume 20 times greater than that seen in the paper by Li Bassi et al. ${ }^{22}$

Another consideration is related to prone positioning of animals $15 \mathrm{~min}$ before the intervention. Turning from the supine to prone position probably recruited collapsed alveoli. In the presence of recruited lungs and no secretions, animals were partially treated. Therefore, hyperinflation maneuvers were unlikely to obtain a measurable effect on respiratory compliance or oxygenation as reported in some clinical studies that investigated these maneuvers..$^{25-27}$

A third concern is related to the method applied to measure mucus displacement, which was conducted by tracking radiopaque tantalum disks placed in the tra- chea. ${ }^{21,23,24,28,29}$ After the tantalum disks were insufflated, they were tracked for $10 \mathrm{~min}$ to define the baseline assessment. Following baseline measures, hyperinflation maneuvers were performed. However, in the prone position, the intrathoracic trachea in swine is oriented upwards, whereas the extrathoracic trachea is almost horizontal. ${ }^{30}$ This orientation facilitates mucus movement toward the glottis due to gravitational force. Thus, it is possible that, during baseline, mucus movement was accelerated by gravity and that the disks were moved to a more horizontal region of the trachea before the maneuvers were applied. In this case, gravity might have favored mucus displacement mostly during baseline, thus explaining the higher mucus transport rate observed at this point. Nevertheless, this hypothesis could have been discarded if there was a group with a sham maneuver. It is also important to highlight that, during baseline, the animals were being ventilated with an expiratory flow bias that was high enough to favor the displacement of mucus toward the glottis, a condition that is not common in clinical practice. ${ }^{31}$

The duration of manual hyperinflation and ventilator hyperinflation also raise some concerns because the maneuvers were too short, lasting only $2 \mathrm{~min}$. In another study conducted by the same research group to investigate the effects of 2 different types of manual chest cage compression on mucus clearance in mechanically ventilated pigs, the maneuvers were applied for 15 min. ${ }^{24}$

In addition, manual hyperinflation was applied differently than recommended in the literature. ${ }^{1}$ In the current study, manual hyperinflation submitted the mucus layer to a burst of peak inspiratory flows until an inspiratory pressure of $40 \mathrm{~cm} \mathrm{H}_{2} \mathrm{O}$ was achieved; only after expiratory flow occurred (see Fig. 1 in Li Bassi et al ${ }^{22}$ ). Considering our hypothesis that there was no secretion retention, this insufflation pattern might have spread out the mucus layer even thinner and thus impeded the transport of mucus via expiratory flow bias. This might explain why manual hyperinflation had the worst performance in terms of mucus clearance rate per animal, as suggested in Figure 6 in Li Bassi et al. ${ }^{22}$

Despite the concerns raised, an interesting result was that manual hyperinflation, as previously described, ${ }^{10}$ produced a highly variable tidal volume, whereas the maneuver was more consistent with the ventilator. This finding reinforces the advantages of applying ventilator hyperinflation instead of manual hyperinflation.

What are the implications of this study? Bench and animal studies can provide valuable insights to our understanding of airway secretion clearance. Although animal studies are not high-level evidence, they can be used to test hypotheses and improve the design of clinical trials. The research by Li Bassi et $\mathrm{al}^{22}$ gives us the opportunity to improve our knowledge regarding 3 important topics: the importance of a right scenario to investigate airway clearance maneuvers, which maneuver should be applied (as 


\section{EDITORIALS}

described by the authors, probably the one that produces a more consistent tidal volume), and the need for an appropriate method to measure secretion clearance, given that the technique affects the results.

In conclusion, this experimental study by Li Bassi et $\mathrm{al}^{22}$ showed unexpected results of the lung hyperinflation maneuvers on the tracheal mucus movement; these results challenge previous findings and call for new investigations. It is unclear whether the tested scenario simulates the ideal condition of retained secretions with reduced compliance, where the lung hyperinflation maneuver could be most effective as a therapeutic technique. Moreover, it is unknown if such a scenario fulfilled the critical factors to allow the expiratory bias flow to move secretions outward from the lungs.

\section{Mauro R Tucci Maria AM Nakamura Nadja C Carvalho \\ Divisao de Pneumologia}

Instituto do Coracao, Hospital das Clinicas HCFMUSP Faculdade de Medicina da Universidade de São Paulo São Paulo, Brazil

Marcia S Volpe

Instituto do Coracao, Hospital das Clinicas HCFMUSP Faculdade de Medicina da Universidade de São Paulo São Paulo, Brazil Department of Sciences of Human Movement Federal University of São Paulo Santos, Brazil

\section{REFERENCES}

1. Paulus F, Binnekade JM, Vroom MB, Schultz MJ. Benefits and risks of manual hyperinflation in intubated and mechanically ventilated intensive care unit patients: a systematic review. Crit Care 2012; 16(4):R145.

2. Branson RD. Secretion management in the mechanically ventilated patient. Respir Care 2007;52(10):1328-1342.

3. Clement AJ, Hubsch SK. Chest physiotherapy by the 'bag squeezing' method: a guide to technique. Physiotherapy 1968;54(10):355359.

4. Paulus F, Binnekade JM, Middelhoek P, Schuitz MJ, Vroom MB. Manual hyperinflation of intubated and mechanically ventilated patients in Dutch intensive care units-a survey into current practice and knowledge. Inten Crit Care Nurs 2009;25(4):199-207.

5. Restrepo RD, Brown JM 2nd, Hughes JM; on behalf of the American Association for Respiratory Care. AARC Clinical Practice Guidelines. Endotracheal suctioning of mechanically ventilated patients with artificial airways 2010. Respir Care 2010;55(6):758-764.

6. Bendixen HH, Hedley-Whyte J, Laver MB. Impaired oxygenation in surgical patients during general anesthesia with controlled ventilation: a concept of atelectasis. N Engl J Med 1963;269:991-996.

7. Neumann P, Berglund JE, Fernández Mondéjar E, Magnusson A, Hedenstierna G. Dynamics of lung collapse and recruitment during prolonged breathing in porcine lung injury. J Appl Physiol 1998; 85(4):1533-1543.
8. Neumann P, Berglund JE, Mondéjar EF, Magnusson A, Hedenstierna G. Effect of different pressure levels on the dynamics of lung collapse and recruitment in oleic-acid-induced lung injury. Am J Respir Crit Care Med 1998;158(5 Pt 1):1636-1643.

9. Markstaller K, Eberle B, Kauczor HU, Scholz A, Bink A, Thelen M, et al. Temporal dynamics of lung aeration determined by dynamic CT in a porcine model of ARDS. Br J Anaesth 2001;87(3):459-468.

10. McCarren B, Chow CM. Manual hyperinflation: a description of the technique. Aust J Physiother 1996;42(3):203-208.

11. Volpe MS, Naves JM, Ribeiro GG, Ruas G, Tucci MR. Effects of manual hyperinflation, clinical practice versus expert recommendation, on displacement of mucus simulant: a laboratory study. PloS One 2018;13(2):e0191787.

12. Stiller K. Physiotherapy in intensive care: an updated systematic review. Chest 2013;144(3):825-847.

13. Berney S, Denehy L. A comparison of the effects of manual and ventilator hyperinflation on static lung compliance and sputum production in intubated and ventilated intensive care patients. Physiother Res Int 2002;7(2):100-108.

14. Anderson A, Alexanders J, Sinani C, Hayes S, Fogarty M. Effects of ventilator vs manual hyperinflation in adults receiving mechanical ventilation: a systematic review of randomised clinical trials. Physiotherapy 2015;101(2):103-110.

15. Benjamin RG, Chapman GA, Kim CS, Sackner MA. Removal of bronchial secretions by two-phase gas-liquid transport. Chest 1989; 95(3):658-663.

16. Volpe MS, Adams AB, Amato MB, Marini JJ. Ventilation patterns influence airway secretion movement. Respir Care 2008;53(10):12871294.

17. Kim CS, Iglesias AJ, Sackner MA. Mucus clearance by two-phase gas-liquid flow mechanism: asymmetric periodic flow model. J Appl Physiol 1987;62(3):959-971.

18. Kim CS, Rodriguez CR, Eldridge MA, Sackner MA. Criteria for mucus transport in the airways by two-phase gas-liquid flow mechanism. J Appl Physiol 1986;60(3):901-907.

19. Freitag L, Long WM, Kim CS, Wanner A. Removal of excessive bronchial secretions by asymmetric high-frequency oscillations. J Appl Physiol 1989;67(2):614-619.

20. Marini JJ, Gattinoni L. Propagation prevention: a complementary mechanism for "lung protective" ventilation in acute respiratory distress syndrome. Crit Care Med 2008;36(12):3252-3258.

21. Li Bassi G, Marti JD, Saucedo L, Rigol M, Roca I, Cabanas M, et al. Gravity predominates over ventilatory pattern in the prevention of ventilator-associated pneumonia. Crit Care Med 2014;42(9):e620-e627.

22. Li Bassi G, Marti JD, Comaru T, Aguilera-Xiol E, Rigol M, Ntoumenopoulos G, et al. Short-term appraisal of the effects and safety of manual versus ventilator hyperinflation in an animal model of severe pneumonia. Respir Care 2019;64(7):760-770.

23. Li Bassi G, Saucedo L, Marti JD, Rigol M, Esperatti M, Luque N, et al. Effects of duty cycle and positive end-expiratory pressure on mucus clearance during mechanical ventilation. Crit Care Med 2012; 40(3):895-902.

24. Marti JD, Li Bassi G, Rigol M, Saucedo L, Ranzani OT, Esperatti M, et al. Effects of manual rib cage compressions on expiratory flow and mucus clearance during mechanical ventilation. Crit Care Med 2013; 41(3):850-856.

25. Paulus F, Veelo DP, de Nijs SB, Beenen LF, Bresser P, de Mol BA, et al. Manual hyperinflation partly prevents reductions of functional residual capacity in cardiac surgical patients-a randomized controlled trial. Crit Care 2011;15(4):R187.

26. Blattner C, Guaragna JC, Saadi E. Oxygenation and static compliance is improved immediately after early manual hyperinflation following myocardial revascularisation: a randomised controlled trial. Aust J Physiother 2008;54(3):173-178. 


\section{EDITORIALS}

27. Choi JS, Jones AY. Effects of manual hyperinflation and suctioning in respiratory mechanics in mechanically ventilated patients with ventilator-associated pneumonia. Aust J Physiother 2005; 51(1):25-30.

28. Li Bassi G, Comaru T, Marti D, Xiol EA, Chiurazzi C, Travierso C, et al. Recruitment manoeuvres dislodge mucus towards the distal airways in an experimental model of severe pneumonia. Br J Anaesth 2019;122(2):269-276.

29. Li Bassi G, Zanella A, Cressoni M, Stylianou M, Kolobow T. Following tracheal intubation, mucus flow is reversed in the semire- cumbent position: possible role in the pathogenesis of ventilatorassociated pneumonia. Crit Care Med 2008;36(2):518-525.

30. Zanella A, Cressoni M, Epp M, Hoffmann V, Stylianou M, Kolobow T. Effects of tracheal orientation on development of ventilator-associated pneumonia: an experimental study. Inten Care Med 2012; 38(4):677-685.

31. Ntoumenopoulos G, Shannon H, Main E. Do commonly used ventilator settings for mechanically ventilated adults have the potential to embed secretions or promote clearance? Respir Care 2011;56(12): $1887-1892$. 